\title{
Metathesis by Molybdenum and Tungsten Catalysts
}

\author{
Richard R. Schrock* \\ Paracelsus Prize 2014 \\ Dedicated to Yves Chauvin, October 10, 1930 - January 27, 2015
}

\begin{abstract}
Carbon-carbon double bonds are an integral part of the chemical industry and are widely found in natural products, from the small and simple (ethylene) to the large and complex. The ability to manipulate carboncarbon double bonds to make other carbon-carbon double bonds in a catalytic and stereospecific fashion has revolutionized the way organic molecules and polymers are made today. This article outlines the development of modern molybdenum and tungsten alkylidene catalysts that can be designed at a molecular level to achieve a given result. Carbon-carbon triple bonds also can be manipulated in a similar manner with the appropriate alkylidyne catalyst. Although the 'alkene metathesis' and 'alkyne metathesis' reactions are now fifty to sixty years old, many problems remain that will require an even more detailed understanding of these most intricate, superficially simple reactions.
\end{abstract}

Keywords: Alkenes · Alkynes · Metathesis · Molybdenum catalysis · Organic Synthesis · Polymer chemistry Tungsten catalysis

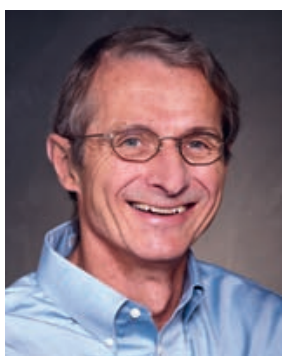

Richard R. Schrock was born in Indiana, but spent his high school years in San Diego, California, and obtained his BA degree in 1967 from the University of California at Riverside. He attended graduate school at Harvard University, from which he received his PhD degree in inorganic chemistry in 1971 (awarded 1972) as a student of J. A. Osborn. He spent one year as an NSF postdoctoral fellow at Cambridge University working in the group of Lord Jack Lewis. In 1972 he accepted a position in the group of George Parshall at the Central Research and Development Department of E. I. duPont

${ }^{*}$ Correspondence: Prof. R. R. Schrock Department of Chemistry

Massachusetts Institute of Technology (MIT) 6-331

77 Massachusetts Ave.

Cambridge, MA 02139, USA

E-mail: rrs@mit.edu de Nemours and Company. He moved to M.I.T. in 1975 where he became full professor in 1980 and in 1989 the Frederick G. Keyes Professor of Chemistry. In 2005 he received the Nobel Prize in chemistry with R. H. Grubbs and Y. Chauvin. He is a member of the National Academy of Sciences and is a Foreign Member of the Royal Society of London. He has published more than 570 research papers, and supervised over 180 PhD students and postdocs.

\section{Introduction}

In the early 1970s organometallic, organic, and polymer chemists were attracted to a new type of catalytic reaction called Olefin Disproportionation by Banks and Bailey, who published results in the open literature in $1964 ;$; $^{[1]}$ the reaction also was reported by Natta in 1964[2] and had appeared in patents filed at duPont ${ }^{[3]}$ and Standard $\mathrm{Oil}^{[4]}$ several years earlier. The basic process, which was shown to be catalyzed by various molybdenum or tungsten, and later rhenium, compounds of unknown type, resulted in an 'exchange' of alkylidene (usually CHR, where $\mathrm{R}=\mathrm{H}$ or alkyl) units in alkenes with one another, e.g. propylene could be equilibrated with ethylene and cis and trans-2-butenes (Eqn. (1), Scheme 1) or norbornene could be polymerized through a 'ring-opening' of its double bonds (Eqn. (2), Scheme 1). Although several mechanisms were proposed, the correct one appeared first in a publication by Hérrison and Chauvin in 1971,[5] namely the reversible reaction between a metal complex that contains a metal-carbon double bond $(\mathrm{M}=\mathrm{CHR})$ and a $\mathrm{C}=\mathrm{C}$ bond to yield an intermediate that contains a metallacyclobutane $\left(\mathrm{MC}_{3}\right)$ ring. A related reaction that involves alkynes was discovered to be catalyzed by a heterogeneous catalyst in 1968 ${ }^{[6]}$ and a homogeneous catalyst in

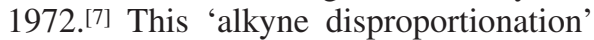
reaction was proposed to consist of a reversible reaction between a $\mathrm{M} \equiv \mathrm{CR}$ bond $(\mathrm{R} \neq \mathrm{H})$ and a $\mathrm{C} \equiv \mathrm{C}$ bond to give all possible alkynes via a metallacyclobutadiene intermediate. ${ }^{[8]}$ Neither process resulted in any positional isomerization of the $\mathrm{C}=\mathrm{C}$ or $\mathrm{C} \equiv \mathrm{C}$ bonds. Although Fischer-type 'low oxidatation state' carbene ${ }^{[9]}$ complexes were known at the time, and the synthesis of carbyne complexes soon followed,[10] they did not promote what came to be known as alkene metathesis ${ }^{[11]}$ and alkyne metathesis, respectively, in the rapid manner often observed for what are now known as 'classical' alkene and alkyne metathesis catalysts. However, experiments first published in 1976 showed that polymerization of cyclic olefins, metathesis of linear olefins, enyne metathesis, and polymerization of acetylenes could be initiated by certain Fischer-type carbene complexes, although new alkylidenes of the same type as the initiator were not observed. ${ }^{[12]}$ Classical metathesis catalysts often are formed from metal oxides on silica or alumina ${ }^{[13]}$ or in 


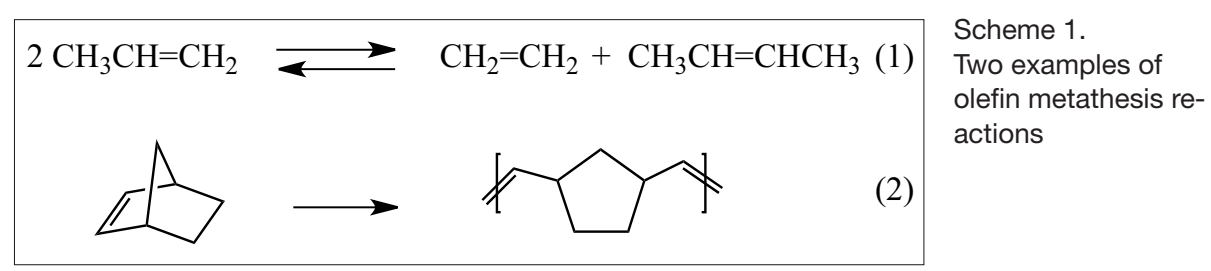

solution from a variety of metal complexes. An alkylating agent is often required, but simply exposing the supported metal oxide to alkenes or alkynes at high temperatures will generate the catalyst through some unknown mechanism or mechanisms.

\section{Discovery of High Oxidation State Multiple Metal-Carbon Bonds}

The first isolated and identified 'high oxidation state' metal complexes that contain $\mathrm{M}=\mathrm{CHR}$ or $\mathrm{M} \equiv \mathrm{CR}$ bonds are $\mathrm{Ta}(\mathrm{CH}-\mathrm{t}-\mathrm{Bu})\left(\mathrm{CH}_{2}-t-\mathrm{Bu}\right)_{3}{ }^{[14]}$ and $\left[\mathrm{Li}\left(\mathrm{N}, \mathrm{N}^{\prime}-\right.\right.$ dimethylpiperazine $)]\left[\mathrm{Ta}(\mathrm{C}-\mathrm{t}-\mathrm{Bu})\left(\mathrm{CH}_{2}-t-\right.\right.$ $\left.\mathrm{Bu})_{3}\right] \cdot{ }^{[15]}$ In these compounds $\mathrm{M}=\mathrm{CHR}$ and $\mathrm{M} \equiv \mathrm{CR}$ bonds are formed through what is essentially deprotonation of an $\alpha$ carbon atom in a neopentyl ligand (to give a neopentylidene ligand) or subsequently deprotonation of a neopentylidene ligand (to give a neopentylidyne ligand), respectively. The ' $\alpha$ hydrogen abstraction' method of preparing metal-carbon double and triple bonds led to the syntheses of Mo and W alkylidene complexes that will metathesize olefins $^{[16]}$ and Mo and W alkylidyne complexes that will metathesize acetylenes. ${ }^{[17]}$ Rhenium alkylidene complexes that will metathesize olefins eventually also were prepared through $\alpha$ hydrogen abstraction reactions in high oxidation state $\mathrm{Re}$ neopentyl complexes. ${ }^{[18]}$ Neopentyl and neophyl $\left(\mathrm{MCH}_{2} \mathrm{CMe}_{2} \mathrm{Ph}\right)$ complexes are especially suited for forming alkylidene and alkylidyne complexes that are relatively stable toward bimolecular coupling of CHR or CR ligands, and are, or can be turned into (through ligand substitution) catalysts for alkene or alkyne metathesis reactions. The size and electronic nature of the ligands dictate the details of the metathesis reaction. Alkylidene and alkylidyne complexes are reformed during the alkene or alkyne metathesis reaction, as has been demonstrated through detection of many alkylidene and alkylidyne analogs during and after a metathesis reaction. It is interesting to note that today molybdenum alkylidyne complexes for alkyne metathesis are prepared through oxidation of Fischer-type alkylidyne complexes, e.g. $\mathrm{Mo}(\mathrm{CPh})(\mathrm{CO})_{4} \mathrm{Br}$ to give $\mathrm{Mo}(\mathrm{CPh})$ (1,2-dimethoxyethane) $\mathrm{Br}_{3},{ }^{[19]}$ a close relative of $\mathrm{W}(\mathrm{C}-t-\mathrm{Bu})(\mathrm{dme}) \mathrm{Cl}_{3}$, that was first prepared in $1981 ;[20]$ replacement of the halides with alkoxide or aryloxide ligands yields catalytically active alkyne metathesis catalysts for both Mo and W.

Most Mo-based or W-based alkene metathesis $^{[16,21]}$ or alkyne metathesis ${ }^{[16,22]}$ catalysts today are four-coordinate. Fourcoordination allows an intermediate fivecoordinate metallacyclobutane or metallacyclobutadiene complex to form readily, and reversibly. Both metallacyclobutane and metallacyclobutadiene complexes have been isolated and characterized crystallographically and shown to be viable catalysts. Alkoxide or aryloxide ligands provide a 'flexible' coordination sphere both in terms of steric protection and electronic tuning through $\pi$ and $\sigma$ pathways. ${ }^{[23]}$ At least one alkoxide or aryloxide ligand is present in the vast majority of alkene or alkyne metathesis catalysts today.

In this article I will concentrate on some recent developments in alkene metathesis catalysts that contain Mo or W, a few of which are shown in Fig. 1. ${ }^{[24]}$ Other articles are available that discuss recent advances in olefin metathesis by Ru catalysts. ${ }^{[25]}$

\section{3. $Z$ and $E$ Selectivity}

One of the reasons why olefin metathesis has achieved what it has is that highly reactive alkylidene complexes can be syn- thesized and manipulated in terms of structures and reactivities in huge variety; this synthetic/mechanistic approach has been critical to catalyst development, and still is critical for further catalyst development today. Most importantly, catalysts can be designed that yield products through kinetic control. An example is the formation of $Z$ olefins, which in many cases is the higher energy isomer of an acyclic olefin. This discovery was greatly assisted through the synthesis of mono aryloxide pyrrolide complexes such as 1, 3, and 4 (Fig. 1). The metallacyclobutane intermediate that ap-

pears to be closest to the transition state for losing an olefin is a trigonal bipyramid in which the aryloxide is in one apical position and the imido group in the other (Fig. 2). A large aryloxide (e.g. a 2,6-disubstituted terphenoxide) was found to limit the metallacycles that can be formed to those in which any substituents on the ring must point away from the large aryloxide ring. ${ }^{[26]}$ Therefore, it is now possible to prepare $Z$ olefins in a large variety from two olefins or in a ring-opening metathesis reaction (see below). It is now also possible to run a $\mathrm{C}=\mathrm{C}$ metathesis coupling in reverse', i.e. to consume a $Z$ olefin selectively in a mixture of $E$ and $Z$ olefins through reaction with ethylene ('ethenolysis'), leaving behind a pure $E$ olefin, a process that is leading to the formation of chemicals from seed oils, many of which are Z-oleic acid derivatives, on an industrial scale.[27] In fact, the problem of selectively forming a $Z$ olefin without subsequent isomerization to $E$ through metathesis was solved through a relatively simple principle, one that has been extended to Ru-based metathesis catalysts; [28] formation of $E$ olefins selectively (through kinetic control) is a problem that remains to be solved.

\section{Organic Synthesis}

The formation of various types of disubstituted or trisubstituted alkenes stereoselectively through olefin metathesis reactions has been, and will continue to be, of tremendous benefit for synthesizing natural products, many of which contain $\mathrm{C}=\mathrm{C}$ bonds; olefin metathesis followed by hydrogenation is also often a relatively

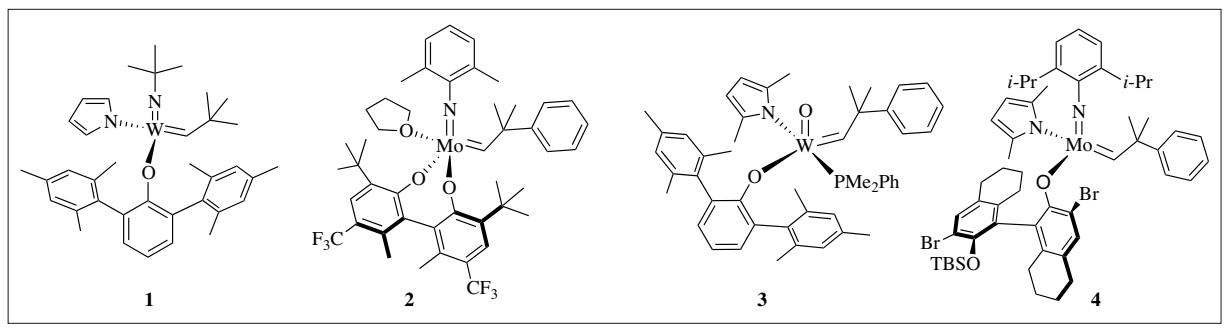

Fig.1. Examples of some recent Mo and W olefin metathesis catalysts.

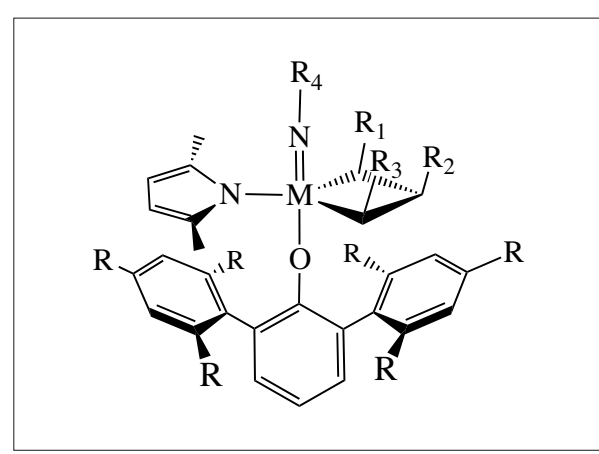

Fig. 2. A TBP metallacyclobutane derived from a MAP complex. 
efficient method to form $\mathrm{C}-\mathrm{C}$ bonds in rings. ${ }^{[29]}$ Several examples of natural products synthesized in the last few years that involve one or more olefin metathesis steps are Epothilone C, ${ }^{[30]}( \pm)$-Tetrapetalone A-Me Aglycon, ${ }^{[31]}$ Nakadomarin A, ${ }^{[30]}$ and (+)-Neopeltolide (Fig. 3). ${ }^{[32]}$ Which of the many different types of Mo- and W-based olefin metathesis catalysts best achieves each of the metathesis reactions is determined through screening procedures, and trends are beginning to emerge. Newer catalysts, e.g. Lewis acid activated ${ }^{[33]}$ or high oxidation state complexes that contain an NHC ligand, ${ }^{[34]}$ have not yet been examined to any significant degree as catalysts for various types of metathesis reactions. It is becoming increasingly clear that small changes in a catalyst can have significant consequences in terms of yields, turnover, and selectivities, and that access to a large variety of catalysts therefore is required for continued advances toward solutions to the problems that remain.

The vast majority of metathesis reactions involve $\mathrm{M}=\mathrm{CHR}$ intermediates in which $\mathrm{R}$ is carbon-based or H. Some alkylidenes in which $\mathrm{R}$ is a heteroatom have now been isolated and appear to react with olefins in a metathesis fashion. ${ }^{[35]}$ Much remains to be done in terms of developing catalysts for metathesis reactions that yield directly functionalized olefins, especially those that can be employed subsequently in catalytic reactions that are not metathesis-based. [36]

\section{Stereospecific Polymerization}

Now that metathesis catalysts can be synthesized in large variety, it has been possible to determine what catalyst is needed to polymerize cyclic olefins to give a polymer with a single structure. Catalysts for ring-opening metathesis polymerization (ROMP) have now been perfected that produce cis,isotactic or cis, syndiotactic polymers with increasing reliability and variety. ${ }^{[37]}$ In 1993 initiators that contain a biphenolate ligand (e.g. 2 in Fig. 1) were found to direct an olefin to one side of the initial $\mathrm{M}=\mathrm{C}$ bond and all subsequent $\mathrm{M}=\mathrm{C}$ bonds to give a cis, isotactic polymer (e.g. Eqn. (3) in Scheme 2 for norbornene itself). ${ }^{[38]}$ Enantiomorphic site control of polymer formation is complemented by the more recent development of MAP initiators (e.g. 1, 3, or 4) that promote formation of cis $\mathrm{C}=\mathrm{C}$ bonds (vide supra) and in the process, formation of cis, syndiotactic polymers as a consequence of the chirality at the metal switching with each insertion of monomer into the $\mathrm{M}=\mathrm{C}$ bond (stereogenic metal control). [39] Hydrogenation of pure cis,isotactic or cis,syndiotactic polymers made from norbornene ${ }^{[40]}$ or di-

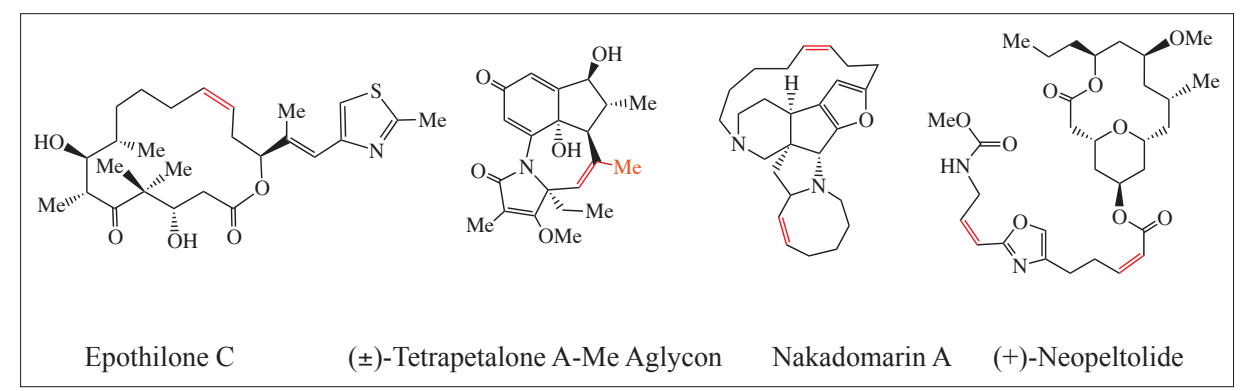

Fig. 3. Several natural product synthesized using at least one olefin metathesis step.

cyclopentadiene ${ }^{[41]}$ yields isotactic or syndiotactic hydrocarbon polymers that are crystalline, high melting, relatively stable to oxygen, and therefore of commercial value. Tungsten oxo alkylidene complexes, especially when activated with $\mathrm{B}\left(\mathrm{C}_{6} \mathrm{~F}_{5}\right)_{3}$, recently have been found to polymerize norbornenes and norbornadienes that are difficult to polymerize stereoselectively, or in some cases, to polymerize at all at $22{ }^{\circ} \mathrm{C}$ with traditional Mo or $\mathrm{W}$ imido alkylidene initiators. ${ }^{[42]}$ The tacticities of several cis,isotactic or cis,syndiotactic polymers have been proven through post polymerization modification. ${ }^{[43]}$

\section{Syn and anti Isomers and Alternating AB Copolymers}

A feature of high oxidation state $\mathrm{M}=\mathrm{CHR}$ complexes of the type shown in Fig. 1 is that they form two isomers, a syn alkylidene isomer in which the $\mathrm{R}$ group points toward the oxo or imido ligand and an anti alkylidene isomer in which the $\mathrm{R}$ group points away from the oxo or imido ligand (Fig. 4); the $\mathrm{CH}_{\alpha}$ bond of the syn isomer is engaged in an 'agostic' interaction $^{[44]}$ with the metal. These syn and anti isomers can interconvert in the absence of an olefin through rotation about the $\mathrm{M}=\mathrm{C}$ bond by $180^{\circ}$ at rates that can differ by as much seven orders of magnitude, e.g. from $\sim 10^{-5} \mathrm{~s}^{-1}$ to $\sim 10^{2} \mathrm{~s}^{-1}$, depending upon the

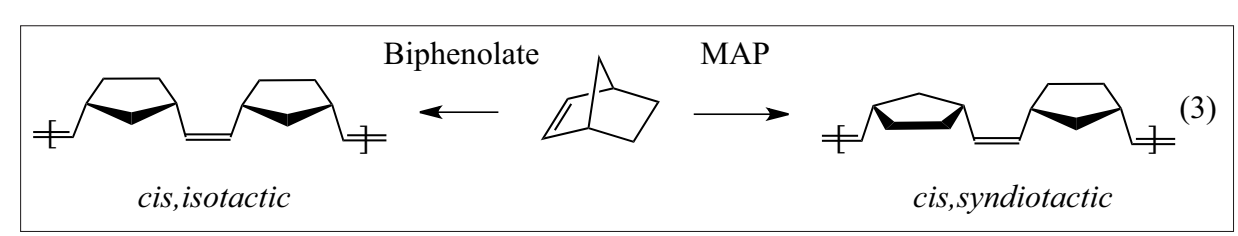

Scheme 2. Formation of stereoregular polymers from norbornene

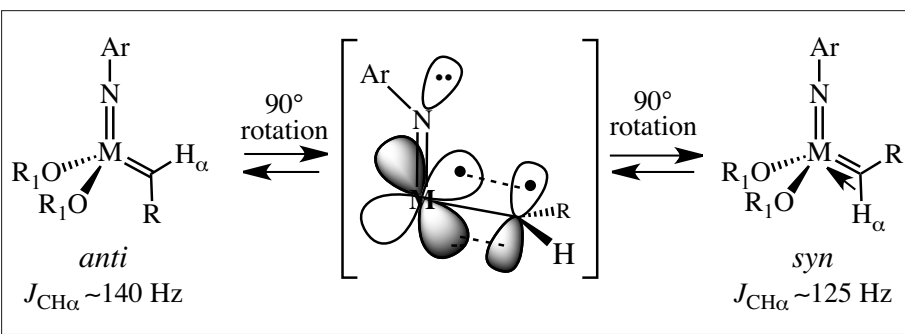

nature of the ligands in the four coordinate alkylidene imido (or oxo complex); rates of the order of $100 \mathrm{~s}^{-1}$ allow these interconversions to be observed in variable temperature proton NMR studies. ${ }^{[45]}$ The alkylidene obtained through rotation by $90^{\circ}$ can be stabilized through formation of a $\pi$ bond employing a d orbital that lies in the N-M-C plane (Fig. 4). Usually the syn isomer is the more stable with $\mathrm{K}_{\mathrm{eq}}$ values as high as 2000 or more, in part because of the agostic $\mathrm{CH}$ interaction. However, the anti isomer, which can be generated at $-78^{\circ} \mathrm{C}$ through photolysis, has been shown to be exceptionally reactive in several cases. When the syn isomer is relatively unreactive and the anti isomer is especially reactive, a metathesis reaction can proceed via the anti isomer without any anti isomer being observed.

In the process of exploring the synthesis of copolymers it was found recently[46] that several alternating $\mathrm{AB}$ metathesis copolymers ${ }^{[47]}$ could be prepared stereoselectively and with as high as $95 \%$ AB alternation from a Mo imido alkylidene initiator (e.g. Scheme 3). All evidence suggests that the mechanism consists of the reaction of $\mathrm{B}$ with anti-MA to give $s y n-\mathrm{MB}$ and one of the trans $\mathrm{C}=\mathrm{C}$ linkages, followed by the reaction of $\mathrm{A}$ with syn-MB to give anti-MA and the other trans $\mathrm{C}=\mathrm{C}$ linkage (Scheme $3)$. The syn-MB isomer is in equilibrium with the anti-MB isomer during polymerization, and the anti-MB isomer is the one
Fig. 4. The equilibrium between syn and anti isomers. 
that is largely observed. Preliminary modeling studies suggest that $\mathrm{k}_{\mathrm{B}}$ is at least several hundred times larger than $\mathrm{k}_{\mathrm{A}}$ (Scheme $3)$. These findings suggest that syn and anti isomers continue to be unappreciated features in many metathesis reactions catalyzed by high oxidation state catalysts, i.e. an unobservable alkylidene isomer that is present in low concentration may be the one that determines the outcome of a metathesis reaction. The $\mathrm{C}=\mathrm{C}$ bonds that are formed in each of the reactions shown in Scheme 1 are trans as a consequence of the monomers being relatively 'large' (B) or 'small' (A) and therefore only trans metallacycles being viable.

\section{Catalysts Supported on Silica}

Olefin metathesis processes have been practiced on a commercial scale for decades, ${ }^{[48]}$ often with a 'classical' heterogeneous catalyst consisting of a metal oxide supported on silica or alumina operating at several hundred degrees centigrade. ${ }^{[13]}$ The largest metathesis process today is the conversion of ethylene into 1-butene through dimerization, isomerization of 1-butene to 2-butenes, then metathesis between ethylene and 2-butenes to give propylene. This olefin conversion technology (OCT) uses a catalyst made from tungsten oxide on silica. The precise nature of the catalytically active centers has never been proven, although high oxidation state oxo alkylidene complexes are the most likely suspects.

Now that tungsten oxo complexes have been prepared, it is time to determine if we can prepare catalysts with a single structure on silica in which all sites are catalytically active at low temperatures, and whose reactivities can be controlled to the degree that is possible now by close analogs in solution. ${ }^{[49]}$ The first steps toward these goals have now been taken. ${ }^{[50]}$ For example, [50b] the reaction of $\mathrm{W}(\mathrm{O})(\mathrm{CH}-t-\mathrm{Bu})(\mathrm{dAdPO})$, $\left(\mathrm{dAdPO}=\mathrm{O}-2,6\right.$-Adamantyl $\left.\mathrm{C}_{6} \mathrm{H}_{3}\right)$ with partially dehydroxylated silica $\left(\mathrm{SiO}_{2-700}\right)$ yields a well-defined silica-supported alkylidene complex, $\left(\mathrm{Si}_{\text {surf }} \mathrm{O}\right) \mathrm{W}(\mathrm{O})$ $\left(\mathrm{CHCMe}_{2} \mathrm{Ph}\right)(\mathrm{dAdPO})$, in high yield that has been fully characterized through solidstate NMR methods (Eqn. (4), Scheme 4). $\left(\mathrm{Si}_{\text {surf }} \mathrm{O}\right) \mathrm{W}(\mathrm{O})\left(\mathrm{CHCMe}_{2} \mathrm{Ph}\right)(\mathrm{dAdPO})$ is a highly active and relatively stable catalyst for the metathesis of internal alkenes with catalyst loadings as low as 50 ppm. It is also active for the homocoupling of terminal alkenes, if ethylene is constantly removed in order to avoid formation of a relatively unreactive square-pyramidal metallacyclobutane complex. Supported catalysts of this type contain only one ligand (dAdPO in Eqn. (4)) that can be varied and the nature of the surface that surrounds the point of attachment $\left(\mathrm{OSi}_{\text {surf }}\right)$ is likely to vary from one attached metal to another. Therefore,
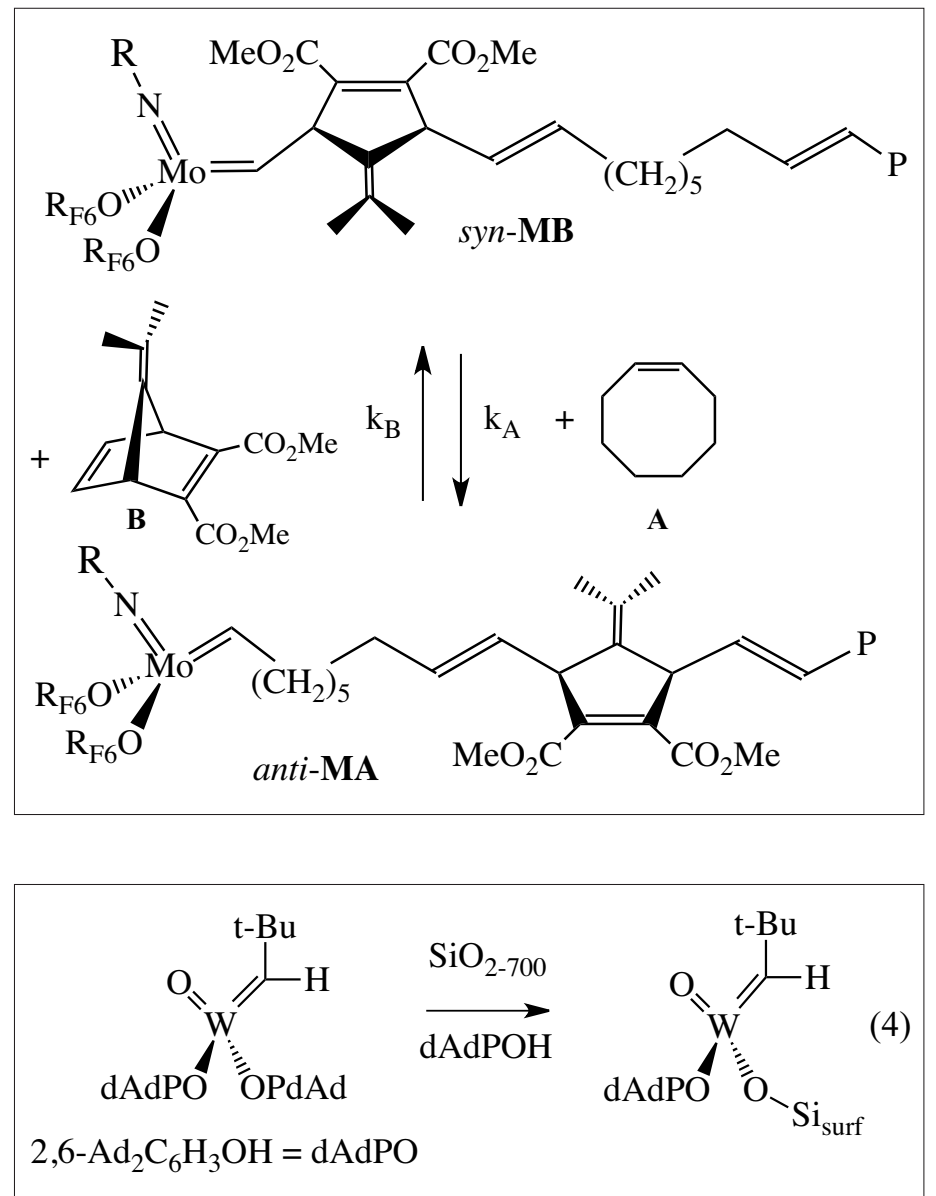

the number of different designs would appear to be more limited than designs for homogeneous catalysts.

\section{Comments}

The olefin metathesis reaction is now approximately 60 years old, but a full understanding of its subtleties and how to develop catalysts to achieve a given result are only beginning to be understood.[51] The role of dispersive forces in sterically crowded molecules of the type described here is a potential further complication that remains to be considered. ${ }^{[52]}$ Although progress in the last several years has been significant, many problems remain to be solved in order to take full advantage of what can be achieved. Metathesis chemistry seems likely to continue to grow, evolve, and become even more useful as these remaining problems are solved.

Received: May 28, 2015

[1] R. L. Banks, G. C. Bailey, Ind. Eng. Chem. Prod. Res. Dev. 1964, 3, 170.

[2] G. Natta, G. Dall'asta, G. Mazzanti, Angew. Chem. Int. Ed. Eng. 1964, 3, 723.

[3] a) H. S. Eleuterio, J. Mol. Catal. 1991, 65, 55; b) H. S. Eleuterio, U. S. Patent 3074918, 1963

[4] E. F. Peters, B. L. Evering, U. S. Patent $2963447,1960$.

[5] J. L. Hérrison, Y. Chauvin, Macromol. Chem. 1971, 141, 161.

[6] F. Pennella, R. L. Banks, G. C. Bailey, Chem Comm. 1968, 1548.

[7] a) A. Mortreux, M. Blanchard, Bull. Soc. Chim. France 1972, 4, 1641; b) A. Mortreux, M. Blanchard, J. Chem. Soc., Chem. Commun. 1974, 786.

[8] T. J. Katz, J. McGinnis, J. Am. Chem. Soc. 1975, 97, 1592.

[9] E. O. Fischer, A. Maasböl, Angew. Chem., Int Ed. Engl. 1964, 3, 580.

[10] E. O. Fischer, G. Kreis, C. G. Kreiter, J. Müller, G. Huttner, H. Lorenz, Angew. Chem., Int. Ed. Engl. 1973, 12, 564

[11] a) N. Calderon, H. Y. Chen, K. W. Scott, Tet. Lett. 1967, 34, 3327; b) K. J. Ivin, J. Mol, 'Olefin Metathesis and Metathesis Polymerization', Academic Press: San Diego, 1997.

[12] a) J. McGinnis, T. J. Katz, S. Hurwitz, J. Am Chem. Soc. 1976, 98, 605; b) T. J. Katz, Angew. Chem. Int. Ed. 2005, 44, 2; c) T. J. Katz in 'Handbook of Metathesis', Vol. 1, Ed. R. H. Grubbs, Wiley-VCH, Weinheim, 2003, p. 47.

[13] S. Lwin, I. E. Wachs, ACS Catal. 2014, 4, 2505

[14] R. R. Schrock, J. Am. Chem. Soc. 1974, 96, 6796.

[15] L. J. Guggenberger, R. R. Schrock, J. Am. Chem. Soc. 1975, 97, 2935.

[16] R. R. Schrock in 'Handbook of Metathesis', Ed. R. H. Grubbs, Wiley-VCH, Weinheim, 2003, p. 8.

Scheme 4. Synthesis of a silica-supported tungsten oxo alkylidene catalyst.
[17] R. R. Schrock in 'Handbook of Metathesis', Ed R. H. Grubbs, Wiley-VCH, Weinheim, 2003, p. 173.

[18] a) R. Toreki, R. R. Schrock, J. Am. Chem. Soc 1990, 112, 2448; b) R. Toreki, G. A. Vaughan, R. R. Schrock, W. M. Davis, J. Am. Chem. Soc. 1993, 115,127

[19] a) A. Mayr, G. A. McDermott, A. M. Dorries, Organometallics 1985, 4, 608; b) B. Haberlag, M. Freytag, C. G. Daniliuc, P. G. Jones, M. 
Tamm, Angew. Chem. Int. Ed. 2012, 51, 13019.

[20] a) J. H. Wengrovius, J. Sancho, R. R. Schrock, J. Am. Chem. Soc. 1981, 103, 3932; b) R. R. Schrock, D. N. Clark, J. Sancho, J. H. Wengrovius, S. M. Rocklage, S. F. Pedersen, Organometallics 1982, 1, 1645.

[21] a) R. R. Schrock in 'Handbook of Metathesis', Vol. 1, 2nd Ed., Eds. R. H. Grubbs, A. G. Wenzel, Wiley-VCH, Weinheim, 2015, pp. 1-32; b) R. R. Schrock, Chem. Rev. 2002, 102, 145; c) R. R. Schrock, Angew. Chem. Int. Ed. 2006, 45, 3748; d) R. R. Schrock, A. H. Hoveyda, Angew. Chem. Int. Ed. 2003, 42, 4592 .

[22] a) R. R. Schrock, Chem. Commun. 2013, 49, 5529; b) A. Fürstner, Angew. Chem. Int. Ed. 2013, 52, 2794; c) R. R. Schrock, C. C. Czekelius, Adv. Syn. Catal. 2007, 349, 55.

[23] R. R. Schrock, Polyhedron 1995, 14, 3177.

[24] a) H. Jeong, J. Axtell, B. Török, R. R. Schrock, P. Müller, Organometallics 2012, 31, 6522; b) R. Singh, C. Czekelius, R. R. Schrock, P. Müller, Organometallics 2007, 26, 2528; c) D. V. Peryshkov, R. R. Schrock, Organometallics 2012, 31, 7278; d) S. J. Meek, S. J. Malcolmson, B. Li, R. R. Schrock, A. H. Hoveyda, J. Am. Chem. Soc. 2009, 131, 16407.

[25] G. C. Vougioukalakis, R. H. Grubbs, Chem. Rev. 2010, 110, 1746.

[26] M. M. Flook, A. J. Jiang, R. R. Schrock, P. Müller, A. H. Hoveyda, J. Am. Chem. Soc. 2009 , $131,7962$.

[27] S. Chikkali, S. Mecking, Angew. Chem. Int. Ed. 2012, 51, 5765.

[28] L. E. Rosebrugh, M. B. Herbert, V. M. Marx, B. K. Keitz, R. H. Grubbs, J. Am. Chem. Soc. 2013, 135, 1276.

[29] Z. Xu, C. W. Johannes, A. F. Houri, D. S. La,
D. A. Cogan, G. E. Hofilena, A. H. Hoveyda, J. Am. Chem. Soc. 1997, 119, 10302

[30] C. Wang, M. Yu, A. F. Kyle, P. Jacubec, D. J. Dixon, R. R. Schrock, A. H. Hoveyda, Chem. Eur. J. 2013, 19, 2726.

[31] P. N. Carlsen, T. J. Mann, A. H. Hoveyda, A. J. Frontier, Angew. Chem., Int. Ed. 2014, 53, 9334

[32] M. Yu, R. R. Schrock, A. H. Hoveyda, Angew. Chem. Int. Ed. 2015, 54, 215.

[33] D. V. Peryshkov, W. P. Forrest, Jr., R. R. Schrock, S. J. Smith, P. Müller, Organometallics 2013, 32, 5256.

[34] M. R. Buchmeiser, S. Sen, J. Unold, W. Frey, Angew. Chem., Int. Ed. 2014, 53, 9384.

[35] E. M. Townsend, S. M. Kilyanek, R. R Schrock, P. Müller, S. J. Smith, A. H. Hoveyda, Organometallics 2013, 32, 4612.

[36] E. T. Kiesewetter, R. V. O'Brien, E. C. Yu, S. J. Meek, R. R. Schrock, A. H. Hoveyda, J. Am. Chem. Soc. 2013, 135, 6026.

[37] R. R. Schrock, Acc. Chem. Res. 2014, 47, 2457.

[38] D. H. McConville, J. R. Wolf, R. R. Schrock, J. Am. Chem. Soc. 1993, 115, 4413.

[39] M. M. Flook, L. C. H. Gerber, G. T. Debelouchina, R. R. Schrock, Macromolecules 2010, 43, 7515 .

[40] B. Autenrieth, R. R. Schrock, Macromolecules 2015, 48, 2493.

[41] B. Autenrieth, H. Jeong, W. P. Forrest, J. C. Axtell, A. Ota, T. Lehr, M. R. Buchmeiser, R. R. Schrock, Macromolecules 2015, 48, 2480.

[42] W. P. Forrest, J. G. Weis, J. M. John, J. C. Axtell, J. H. Simpson, T. M. Swager, R. R. Schrock, J. Am. Chem. Soc. 2014, 136, 10910.

[43] J. Hyvl, B. Autenrieth, R. R. Schrock, Macromolecules 2015, 48, 3148 .

[44] M. Brookhart, M. L. H. Green, G. Parkin, Proc.
Nat. Acad. Sci. 2007, 104, 6909.

[45] J. H. Oskam, R. R. Schrock, J. Am. Chem. Soc. 1992, 114, 7588 .

[46] H. Jeong, J. M. John, R. R. Schrock, A. H Hoveyda, J. Am. Chem. Soc. 2015, 136, 2239.

[47] For other examples see a) L. Tan, K. A. Parker, N. S. Sampson, Macromolecules 2014, 47, 6572; b) L. Ding, X.-Q. Zheng, R. Lu, J. An, J. Qiu, Polym. Int. 2014, 63, 997; c) C. S. Daeffler, R. H. Grubbs, Macromolecules 2013, 46, 3288 ; d) K. Vehlow, D. Wang, M. R. Buchmeiser, S. Blechert, Angew. Chem., Int. Ed. 2008, 47, 2615; e) M. F. Ilker, E. B. Coughlin, Macromolecules 2002, 35, 54 .

[48] A. M. Rouhi, Chem. Eng. News 2002, 80, 29.

[49] C. Copéret, M. Chabanas, R. Petroff SaintArroman, J.-M. Basset, Angew. Chem. Int. Ed. 2003, 42, 156.

[50] a) M. P. Conley, V. Mougel, D. V. Peryshkov, W. P. Forrest, D. Gajan, A. Lesage, L. Emsley, C. Copéret, R. R. Schrock, J. Am. Chem. Soc 2013, 135, 19069; b) M. P. Conley, W. P. Forrest, V. Mougel, G. Siddiqi, O. V. Safonova, C. Copéret, R. R. Schrock, Angew. Chem. Int Ed. 2014, 53, 14221.

[51] X. Solans-Monfort, C. Copéret, O. Eisenstein, Organometallics 2015, 34, 1668.

[52] See, for example, a) J.-D. Guo, S. Nagase, P. P. Power, Organometallics 2015, 34, 1668; b) E. Lyngvi, I. A. Sanhueza, F. Schoenebeck, Organometallics 2015, 34, 805. 